\title{
Barriers and motivators for uptake of cervical cancer prevention strategies in Eastern Europe: the perspective from Latvia
}

\author{
Hersha Patel ${ }^{1}$, Susan M. Sherman², Kristine Pčolkina³ , Kristīne Strazdiṇa³, Ilze Viberga³, Charles W. Redmann ${ }^{4}$ \\ Jana Zodzika5, Dace Rezeberga5, Esther L. Moss ${ }^{6 凶}$
}

\begin{abstract}
Introduction: The incidence of cervical cancer (CC) in eastern European countries is high; however, uptake of available prevention strategies is suboptimal. We explored knowledge, behaviors, and attitudes toward CC prevention strategies in Latvian women.

Methods: A mixed-methods study of Latvian women, consisting of surveys and semi-structured interviews, was conducted in Riga, Latvia in September and October 2015.

Results: Altogether, 158 surveys were completed and 10 interviews were conducted. In total, $87 \%(n=135)$ had previously had a smear test, and $67 \%(n=105)$ correctly identified that cervical cytology was performed to identify precancerous changes. The practice of annual gynecological checkups was prevalent, and many believed it to be synonymous with cervical screening. Detailed knowledge of human papillomavirus (HPV) infection and the HPV vaccine was deficient, although $73 \%(n=115)$ and $70 \%(n=90)$, respectively, claimed to have heard of them. Negative attitudes existed regarding the HPV vaccine due to fear of potential side effects. On learning that HPV was transmitted through sexual contact, the notion of testing positive for HPV was met with shame and embarrassment.

Conclusions: A small proportion of Latvian women are over-screened, whereas many women remain unscreened. The main contributing factor for this was their poor understanding of the roles that cervical screening and HPV vaccination play in preventing CC.
\end{abstract}

Keywords: cervical screening, cervical cancer prevention, Latvia, HPV, HPV vaccination, Eastern Europe

Received: 6 April 2019 | Returned for modification: 24 June 2019 | Accepted: 29 July 2019

\section{Introduction}

Mortality related to cervical cancer (CC) is disproportionally higher in Eastern Europe than in Western Europe $(1,2)$. This gap is likely to widen as CC mortality in eastern European continues to increase (3). The absence of national cervical screening (CS) programs (CSP) has been reported as a significant contributing factor $(4,5)$, with countries that have established structured CSPs having demonstrated a reduction in mortality and incidence of CC (6).

In recent years, the majority of eastern European countries have introduced CSPs; however, they differ in their organizational infrastructures. For example, the Czech Republic offers CS annually, Estonia's screening interval is 5 years, and in Latvia it is 3 years (7-9). CS coverage in these countries varies significantly, ranging from $8 \%$ in Romania to $72 \%$ in Slovenia (7-9). Low coverage of the target populations in some eastern European countries is often due to out-of-program opportunistic screening programs, and they are not underpinned by robust quality assurance mechanisms (7-9). Consequently, the impact of these CSPs appears limited, with very little reduction in CC incidence or mortality rates.

Latvia harbors one of the highest CC incidence and mortality rates in Europe (3). The incidence increased substantially from $8.9 / 100,000$ in 1989 (10), when screening was a mandatory component of annual health checks, to 25.1/100,000 in 2014 (11), following discontinuation of compulsory screening in 1989 and 20 years of opportunistic-only screening (10). A fully-funded national CSP started in 2009, and published data have reported screening coverage to reach a maximum of $59 \%$, with $41 \%$ of these women ac- cessing screening outside the national program (8). Following the implementation of a state-funded human papillomavirus (HPV) vaccination program in Latvia (2010), uptake of the HPV vaccine has been low (53.4\% in 2012) (12).

Not all eastern European countries face the same issues when trying to encourage CS participation; however, there are commonalities as a result of their shared experiences during the Soviet era. Taking Latvia as representative of many eastern European countries, we have performed an in-depth analysis of the knowledge, behaviors, and attitudes regarding CC prevention strategies in women to inform screening programs and educational campaigns.

\section{Methods}

Ethical approval was obtained from the University of Latvia ethics commission board (August 13th, 2015).

A mixed-methods study of surveys and one-to-one semi-structured qualitative interviews was conducted. Latvian women in Riga age 20 and older were eligible for the study. The age criterion was not based on the Latvian CSP recommendations (25-69 years) because many women are opportunistically screened outside the program (10).

\section{Survey}

The survey was developed following a literature search and preprotocol patient and public involvement work (PPI). The 28-item survey explored existing screening behaviors, CC and CS knowl- 
edge, and HPV and HPV vaccine awareness. Pre-validated questions (13) were incorporated into the survey. The overall face validity of the instrument was confirmed by peer review from experts within the specialty and the PPI groups. The survey was developed in English and was translated into Latvian by the Latvian researchers.

A purposive sampling approach was adopted between September and October 2015 to recruit patients from a state-funded General Practitioner (GP) surgery in Riga and colposcopy clinics at Riga East Clinical University Hospital. The women completed the anonymous survey prior to their consultations. The data were entered into the Statistical Package for Social Sciences (SPSS Inc. Chicago, IL, USA), version 22. Descriptive statistics were generated for the responses and a chi square test or Fisher exact test was used for analysis. $P$-values were assessed using two-sided tests, and statistical significance was taken as a cutoff of $p \leq 0.05$.

\section{Semi-structured interviews}

Participants volunteered at the end of the survey to be interviewed. The objective of the interviews was to obtain a detailed understanding of screening behaviors, access to healthcare in Latvia, and issues surrounding HPV testing and vaccination. HP (first author) conducted the interviews in English, and an interpreter was offered to the participants.

The interviews were audio recorded with permission and transcribed verbatim into English. An inductive framework method of thematic analysis (14) was used for transcript analysis, facilitated by NVivo software.

Table 1 | Socio-demographic characteristics.

\begin{tabular}{|c|c|}
\hline Variable & Value \\
\hline Age (median/range) & $36(21-71)$ \\
\hline \multicolumn{2}{|l|}{ Relationship status, $n(\%)$} \\
\hline Married & 78 (49) \\
\hline Widowed & $4(3)$ \\
\hline Divorced & $11(7)$ \\
\hline Separated & $6(4)$ \\
\hline In a civil partnership & $17(11)$ \\
\hline In a relationship & $18(11)$ \\
\hline Cohabiting & $18(11)$ \\
\hline Single & $6(4)$ \\
\hline \multicolumn{2}{|l|}{ Education, $n(\%)$} \\
\hline No formal qualifications & $2(1)$ \\
\hline Trade/technical/vocational & $38(24)$ \\
\hline GCSE / O level or equivalent & $29(18)$ \\
\hline A level or equivalent & $7(4)$ \\
\hline Bachelor's degree & $49(31)$ \\
\hline Graduate degree & $28(18)$ \\
\hline Other & $5(3)$ \\
\hline \multicolumn{2}{|l|}{ Employment status, $n(\%)$} \\
\hline Employed full time & $114(72)$ \\
\hline Employed part time & $13(8)$ \\
\hline Unemployed & $12(8)$ \\
\hline Retired & $5(3)$ \\
\hline Housewife & $14(9)$ \\
\hline \multicolumn{2}{|l|}{ Ethnicity, $n(\%)$} \\
\hline Latvian & $151(96)$ \\
\hline Russian & $3(2)$ \\
\hline Polish & $2(1)$ \\
\hline Other & $2(1)$ \\
\hline \multicolumn{2}{|l|}{ Country of birth, $n(\%)$} \\
\hline Latvia & $154(97)$ \\
\hline Russia & $3(2)$ \\
\hline Other & 1 (1) \\
\hline
\end{tabular}

GCSE $=$ General Certificate of Secondary Education.

\section{Results}

\section{Survey}

Altogether, 158/200 surveys were completed, 25 from primary care and 133 from secondary care, with an overall response rate of $79 \%$. Detailed demographics are presented in Table 1.

Most women $(67 \%, n=105)$ understood that the smear test is a screening tool to identify precancerous cervical changes and that it lacks diagnostic ability $(72 \%, n=113$; Table 2$)$. Around half $(53 \%, n=83)$ selected only the true options for the question "Why are cervical smear tests performed?"

Most women had heard of HPV $(73 \%, n=115 / 157)$ but demonstrated limited knowledge of HPV (Table 3). Among women who had either heard of HPV or were not sure if they had $(10 \%, n=16)$, median scores for general HPV knowledge and HPV testing ques-

Table 2 | Cervical screening behavior and knowledge.

\begin{tabular}{|c|c|c|}
\hline Question & Response & Value \\
\hline \multicolumn{3}{|c|}{$\begin{array}{l}\text { Why are cervical smear tests performed? (select all true options) } \\
(n=157), n(\%)\end{array}$} \\
\hline \multirow[t]{2}{*}{ To diagnose precancerous cervical cells } & Correct & $105(67)$ \\
\hline & Incorrect & $52(33)$ \\
\hline \multirow[t]{2}{*}{ To diagnose cervical cancer } & Correct & $113(72)$ \\
\hline & Incorrect & $44(28)$ \\
\hline \multirow[t]{2}{*}{ To detect STDs } & Correct & $151(96)$ \\
\hline & Incorrect & $6(4)$ \\
\hline \multirow[t]{2}{*}{ As part of a full gynecological exam } & Correct & $121(77)$ \\
\hline & Incorrect & $36(23)$ \\
\hline \multicolumn{3}{|c|}{ Aware of free cervical screening in Latvia? $(n=155), n(\%)$} \\
\hline & Yes & $135(87)$ \\
\hline & No & $20(13)$ \\
\hline \multicolumn{3}{|c|}{ Source of information about smear tests? $(n=135), n(\%)$} \\
\hline & GP & $26(19)$ \\
\hline & Friends & $2(1)$ \\
\hline & $\begin{array}{l}\text { Smear invitation } \\
\text { letter }\end{array}$ & $87(64)$ \\
\hline & Other & 24 (18) \\
\hline
\end{tabular}

Recommended screening commencement age in Latvia? $(n=117)$, median (range)

\begin{tabular}{|c|c|}
\hline & $25(15-50)$ \\
\hline \multicolumn{2}{|l|}{ Recommended screening frequency in Latvia? $(n=139), n(\%)$} \\
\hline Don’t know & $1(1)$ \\
\hline Every 6 months & $10(7)$ \\
\hline Every year & $46(33)$ \\
\hline Every 3 years & $82(59)$ \\
\hline \multicolumn{2}{|l|}{ Have you ever had a smear test? $(n=155), n(\%)$} \\
\hline Yes & $135(87)$ \\
\hline No & $16(10)$ \\
\hline Not sure & $4(3)$ \\
\hline \multicolumn{2}{|l|}{ Age of first smear test? $(n=121), n(\%)$, median (range) } \\
\hline & $25(18-55)$ \\
\hline \multicolumn{2}{|l|}{ Country of first smear test? $(n=128), n(\%)$} \\
\hline Latvia & $122(95)$ \\
\hline Other & $3(2)$ \\
\hline Not sure & $3(2)$ \\
\hline \multicolumn{2}{|l|}{ Timing of most recent smear test? $(n=149), n(\%)$} \\
\hline Never had one & $15(10)$ \\
\hline $0-3$ years & $124(83)$ \\
\hline $4-5$ years & $8(5)$ \\
\hline $\begin{array}{c}\text { More than } 5 \\
\text { years }\end{array}$ & $2(1)$ \\
\hline \multicolumn{2}{|l|}{ Always attend for a smear test? $(n=145), n(\%)$} \\
\hline Yes & $88(61)$ \\
\hline No & $37(25)$ \\
\hline $\begin{array}{c}\text { Cannot } \\
\text { remember }\end{array}$ & $20(14)$ \\
\hline
\end{tabular}

STDs = sexually transmitted diseases, $\mathrm{GP}=$ general practitioner. 
tions were 7/15 (range 0-15) and 4/6 (range 0-6), respectively. Fewer women responded to the questions about the HPV vaccine; $70 \%(n=90 / 129)$ had heard of the HPV vaccine and only $4 \%(n=$ 5) had received it.

Younger age was significantly correlated with general HPV knowledge (-0.28 [Spearman's rho correlation coefficient]: $p<$ o.01) and HPV vaccine knowledge ( -0.21 [Spearman's rho correlation coefficient]: $p=0.01)$. Higher educational attainment was associated with a higher HPV testing knowledge score (o.19 [Spearman's rho correlation coefficient]: $p=0.02$ ). Neither marital nor employment status showed any significant correlations.

\section{Semi-structured interviews}

Ten interviews were conducted; five women from primary care and five from secondary care. Their median age was 35 years (range 20-62 years). Details in parentheses following quotes represent the participant's identification number (P) and age (in years). An asterisk $\left({ }^{\star}\right)$ marks quotes obtained via an interpreter.

\section{Doctor-patient relationship}

It was apparent that there was considerable trust vested in doctors; their advice was not to be questioned nor was it felt necessary to conduct independent research. The women were willing to alter health behaviors (e.g., frequency of CS) based purely on the recommendation of the doctor: "So if the doctor says that you need to do this, she will do that. She is not one of those people who spend hours researching the internet, yes" * $(\mathrm{P} 8,43)$.

\section{Annual gynecological checkups}

The practice of annual gynecological checkups was prevalent, and it appears to have been passed down the generations and accept-

Table 3 | Human papillomavirus (HPV) and HPV vaccine knowledge.

\begin{tabular}{|c|c|c|}
\hline General HPV knowledge $(n=116)^{\star}$ & Correct, $n(\%)$ & Incorrect, $n(\%)$ \\
\hline HPV is very rare & $110(95)$ & $6(5)$ \\
\hline HPV always has visible signs or symptoms & $107(92)$ & $9(8)$ \\
\hline HPV can cause cervical cancer & $88(76)$ & $28(24)$ \\
\hline HPV can be passed by genital skin-to-skin contact & $27(23)$ & $89(77)$ \\
\hline There are many types of HPV & $54(47)$ & $62(53)$ \\
\hline HPV can be passed on during sexual intercourse & $59(51)$ & $57(49)$ \\
\hline HPV can cause genital warts & $26(22)$ & $90(78)$ \\
\hline Men cannot get HPV & $107(92)$ & $9(8)$ \\
\hline Using condoms reduces the risk of getting HPV & $47(41)$ & 69 (59) \\
\hline HPV can be cured with antibiotics & $105(90)$ & $11(10)$ \\
\hline Having many sexual partners increases the risk of getting HPV & $55(47)$ & $61(53)$ \\
\hline HPV usually does not need any treatment & $7(6)$ & $109(93)$ \\
\hline Most sexually active people will get HPV at some point in their lives & $24(21)$ & $92(79)$ \\
\hline A person could have HPV for many years without knowing & $59(51)$ & $57(49)$ \\
\hline Having sex at an early age increases the risk of getting HPV & $32(28)$ & $84(72)$ \\
\hline \multicolumn{3}{|l|}{ HPV testing knowledge $(n=91)$} \\
\hline An HPV test can tell how long you have had an HPV infection & $82(90)$ & $9(10)$ \\
\hline If a woman tests positive for HPV she will definitely get cervical cancer & $85(93)$ & $6(7)$ \\
\hline An HPV test can be done at the same time as a smear test & $58(64)$ & $33(36)$ \\
\hline HPV testing is used to indicate if the HPV vaccine is needed & $73(79)$ & $18(20)$ \\
\hline When you have an HPV test, you get the results the same day & $80(88)$ & $11(12)$ \\
\hline If an HPV test shows that a woman does not have HPV, her risk of cervical cancer is low & $41(45)$ & $50(55)$ \\
\hline \multicolumn{3}{|l|}{ HPV vaccine knowledge $(n=80)$} \\
\hline HPV vaccines require two doses & $35(44)$ & $45(56)$ \\
\hline HPV vaccines offer protection against all sexually transmitted infections & $78(98)$ & $2(2)$ \\
\hline HPV vaccines are most effective if given to people who have never had sex & $57(71)$ & $23(29)$ \\
\hline Someone who has had the HPV vaccine cannot develop cervical cancer & $70(88)$ & $10(12)$ \\
\hline HPV vaccines offer protection against most cervical cancers & $45(56)$ & $35(44)$ \\
\hline One HPV vaccine offers protection against genital warts & $7(9)$ & $73(91)$ \\
\hline Girls who have had the HPV vaccine do not need to have smear tests when they are older & $78(98)$ & $2(2)$ \\
\hline
\end{tabular}

ed as the norm. Reproductive organs were seen as more valuable than other organs, whereby they needed to be protected, hence the need for prophylactic screening: "but I know from childhood, from teenage years, that you have to go to the gynecologist at least every year to check everything" $(\mathrm{P} 4,34)$.

Despite obvious concern regarding their reproductive organs, the women had little understanding of the examinations or tests that were performed during their annual checkups. The gynecologist was responsible for determining which tests were required: "she comes and the gynecologist does A, B, and C" *(P9, 37).

\section{Cervical screening behaviors: motivators}

Most women attended CS annually, with some going as frequently as every 3 to 6 months. They described a feeling of "fear" that something would be missed if they waited the recommended 3 years, and having annual smears made them feel "safe.” The reason for the national CSP not recommending more frequent screening was believed to be financially motivated: "I think it's just connected with ... government money, but I think every woman should go at least once a year at her own expense" $\left(\mathrm{P}_{5}, 35\right)$.

The practice of annual smears and checkups appeared to be embedded in women's culture, and the gynecologist further reinforced it. Their motives for screening included the gynecologist recommending it: "just as usual" $\left(\mathrm{P}_{3}, 62\right)$, "I think you have to do this" (P4, 34), and "because I was pregnant and it's normal to know about my health" $\left(\mathrm{P}_{5}, 35\right)$. It was not clear whether they fully understood that the CS was different from the annual gynecological checkup.

\section{Cervical screening behaviors: barriers}

Perceived barriers to screening included that many women may not have heard of CS, and so they simply ignore the invitation let- 
ters. Access was an issue, particularly for women who resided in remote villages. Time played a role in two ways; the length of time that one would have to wait to receive an appointment, and that women were generally too busy to make time. Finally, because they were asymptomatic, screening was not prioritized.

\section{Knowledge and understanding of cervical screening, cervical cancer, and HPV}

Many women were aware of the national CSP in Latvia, mainly from receiving the smear invitation letter. Most women were able to provide an accurate description of what a smear test involved and its purpose; however, others were less clear and believed that it was testing for "some kind of fungus or stuff like that" $(\mathrm{P} 1,20)$.

Knowledge regarding the management of an abnormal smear was poor, with an assumption that further examination was required but no knowledge of what form this might take. There was a lack of awareness of the consequences of multiple treatments.

The scale of the disease burden in Latvia was underestimated: "nobody has heard about cancer of the cervix" $(\mathrm{P} 1,20)$.

Risk factors for developing CC were stated as multiple partners, hereditary, lifestyle, multiparity, and a connection to uterine fibroids. The causal relationship between HPV and the development of CC was acknowledged, but not the strength/seriousness of the association.

Many had heard of HPV, but detailed knowledge was variable. The prevalence of HPV in Latvian women was underestimated. Some women correctly identified that HPV was transmitted through sexual contact, whereas others were not sure how it was transmitted.

The women claimed to have heard of the HPV vaccine when prompted, but had limited knowledge: "She does know that the vaccine is intended to prevent $\mathrm{CC}$, but she does not know the connection between the vaccine and $\mathrm{HPV} ” *(\mathrm{P} 8,43)$.

\section{Beliefs, perceptions, and attitudes toward HPV}

Latvia is described as a religious country, and therefore the women believed that HPV would not be spoken of openly, stemming from the misconception that HPV infection is synonymous with sexual promiscuity: "Latvians are quite religious, so they don't like to talk about it, especially like when a person is changing partners quite often" (P10, 30).

Negative views were expressed toward the HPV vaccine because it was felt that the available scientific information was inadequate. HPV was felt to be a relatively new concern: "30 years ago we never heard about this problem" $(\mathrm{P} 4,34)$. Fear of the side effects of such a new vaccine was reported as a major barrier to vaccine acceptance.

\section{Emotions}

"Scared" and "shame" were the most frequently quoted emotions. Participants were "scared of the unknown" $(\mathrm{P} 1,20)$, "scared because ... they will discover something" (P10, 30), and "afraid of cancer in case it develops within 3 years" $\left(\mathrm{P}_{3}, 62\right)$. They fear that something may be missed or are afraid of starting a new relationship out of fear that they may contract the virus again.

"Shame" was used alongside the possibility of discussing sexual behaviors with parents or healthcare professionals: "not everybody talks about it, and in different cultures it's like a shame to talk about it” (P10, 30).

\section{Discussion}

This mixed-methods study highlights the complex interactions that exist between knowledge, self-perceived health, and importance of health that govern CC prevention uptake. There was a lack of awareness of the high incidence of CC in Latvia, resulting in poor self-perceived susceptibility, as well as an ingrained cultural practice of annual gynecology checkups and a mistrust of the government-funded programs.

Attendance for screening in this cohort was higher (87\%) than the national screening coverage of $59 \%$ (8), which is consistent with the majority of participants for the survey being recruited from colposcopy clinics. Worryingly, 14\% (19/130) of the women recruited from colposcopy clinics claimed they had not previously had a smear test. It was unclear whether all the women interviewed understood the difference between annual gynecological checkups and CS. An Estonian study found that a recent visit to the gynecologist was the most commonly stated reason for not attending CS (15). Attending screening opportunistically was prevalent in this cohort. One pitfall of opportunistic screening is the performance of unnecessary diagnostic procedures and treatments (16). Pelvic examinations have been described by women as causing discomfort and embarrassment (17); a bad experience with an unnecessary pelvic examination may jeopardize future participation with CS (18). The practice of gynecological screening is also prevalent in other eastern European countries $(19,20)$, which might explain the low uptake of national CS in Eastern Europe $(4,5)$.

Overall there was good awareness of the Latvian national CSP, and therefore lack of compliance would suggest there is an issue with acceptability and/or communication about the justification of the recommended practice. Healthcare professionals may also find the national program problematic because some women cited their gynecologist's recommendation as a reason for opportunistic CS. This study showed that there was a great amount of trust placed in the advice of the doctor, and therefore one could argue that to increase participation with national CS the focus should be on changing the attitudes of healthcare professionals.

The survey and interviews revealed that detailed HPV and HPV vaccine knowledge was poor among Latvian women; although HPV testing is not routinely part of the CSP in Latvia (7), the HPV vaccine has been available since 2010 (21). Concerns regarding HPV vaccine side effects and that the vaccine is "new/experimental" have also been found in Romanian mothers, among whom there is low vaccine uptake (22), despite the HPV vaccine not being found to be associated with any serious adverse effects (23). Mothers' own participation in preventative healthcare has been shown to be associated with enhanced engagement of daughters with screening and vaccination (24). In our cohort it was evident that women had a heightened sense of protection for their reproductive organs but did not fully appreciate the benefits of primary prevention. Therefore, only the practice of annual gynecological checkups was being passed down through the generations.

Overall there was poor knowledge about CC and its causes. Lack of knowledge and awareness has been associated with poor screening attendance (25). Poor knowledge levels can result in lower self-perceived susceptibility. It is difficult to accurately assess the CS behaviors of the women in this study because many did not understand the difference between their routine gyneco- 
logical checkup and CS. It is possible that they had a smear test performed at each of their checkups or that they never had a smear test performed. The opportunistic screening described was performed in the private sector, and therefore no databases exist and implementing any quality assurance is difficult.

Participation in organized CS that has good quality assurance can be increased through greater patient engagement. To achieve this, awareness of CC needs to be increased, and the use of media outlets provides one possible method of accomplishing this. In addition, healthcare professionals have a vital role to play in patient education and in endorsing participation in the national CSP.

The study had some limitations. Participants were recruited from a single GP practice and single hospital institute, which could result in facility bias and may not be representative of the general population. The interview participants might represent a group who are inherently more likely to engage with screening because they volunteered to take part in the study. Targeting women who do not attend screening is very challenging, and it is just as important to look at what motivates women to attend screening as it to explore the barriers to screening in non-attenders (26).

\section{Conclusions}

The current CS behaviors in Latvian women appear to be governed by their lack of knowledge of the principles of screening and causes of CC. The results could be extrapolated to many eastern European countries that share a common Soviet heritage with Latvia, and they could give clinicians and policymakers insights into the misconceptions that need to be overcome to achieve greater patient engagement with CC prevention initiatives.

\section{Acknowledgements}

We would like to thank all the women that took time to participate in this study.

\section{Funding}

This study was conducted as part of a Sims Black Travelling Fellowship, which was awarded to CWE Redman and EL Moss by the Royal College of Obstetricians and Gynaecologists.

\section{References}

1. Arbyn M, Autier P, Ferlay J. Burden of cervical cancer in the 27 member states of the European Union: estimates for 2004. Ann Oncol. 2007;18:1423-5.

2. Arbyn M, Raifu AO, Autier P, Ferlay J. Burden of cervical cancer in Europe: estimates for 2004. Ann Oncol. 2007;18:1708-15.

3. Arbyn M, Raifu AO, Weiderpass E, Bray F, Anttila A. Trends of cervical cancer mortality in the member states of the European Union. Eur J Cancer. 2009;45:26408.

4. Poljak M, Seme K, Maver PJ, Kocjan BJ, Cuschieri KS, Rogovskaya SI, et al. Human papillomavirus prevalence and type-distribution, cervical cancer screening practices and current status of vaccination implementation in central and eastern Europe. Vaccine. 2013;31 Suppl 7:H59-70.

5. Rogovskaya SI, Shabalova IP, Mikheeva IV, Minkina GN, Podzolkova NM, Shipulina OY, et al. Human papillomavirus prevalence and type-distribution, cervical cancer screening practices and current status of vaccination implementation in Russian Federation, the western countries of the former Soviet Union, Caucasus region and Central Asia. Vaccine. 2013;31 Suppl 7:H46-58.

6. Landy R, Pesola F, Castañón A, Sasieni P. Impact of cervical screening on cervical cancer mortality: estimation using stage-specific results from a nested casecontrol study. Br J Cancer. 2016;115:1140-6.

7. Maver PJ, Seme K, Korac T, Dimitrov G, Dobrossy L, Engele L, et al. Cervical cancer screening practices in central and eastern Europe in 2012. Acta Dermatovenerol Alp Pannonica Adriat. 2013;22:7-19.

8. Elfström KM, Arnheim-Dahlström L, von Karsa L, Dillner J. Cervical cancer screening in Europe: quality assurance and organisation of programmes. Eur J Cancer. 2015;51:950-68.

9. Kesic V, Poljak M, Rogovskaya S. Cervical cancer burden and prevention activities in Europe. Cancer Epidemiol Biomarkers Prev. 2012;21:1423-33.

10. Viberga I, Poljak M. Cervical cancer screening in Latvia: a brief history and recent improvements (2009-2011). Acta Dermatovenerol Alp Pannonica Adriat. 2013;22:27-30.

11. Kornete A, Pumpure E, Macuks R. Analysis of invasive cervical cancer cases in Latvia. Int J Reprod Contracept Obstet Gynecol. 2016;5:3789-94.

12. Seme K, Maver PJ, Korac T, Canton A, Castkova J, Dimitrov G, et al. Current status of human papillomavirus vaccination implementation in central and eastern Europe. Acta Dermatovenerol Alp Pannonica Adriat. 2013;22:21-5.

13. Waller J, Ostini R, Marlow LA, McCaffery K, Zimet G. Validation of a measure of knowledge about human papillomavirus (HPV) using item response theory and classical test theory. Prev Med. 2013;56:35-40.
14. Gale NK, Heath G, Cameron E, Rashid S, Redwood S. Using the framework method for the analysis of qualitative data in multi-disciplinary health research. BMC Med Res Methodol. 2013;13:117.

15. Kivistik A, Lang K, Baili P, Anttila A, Veerus P. Women's knowledge about cervical cancer risk factors, screening, and reasons for non-participation in cervical cancer screening programme in Estonia. BMC Womens Health. 2011;11:43.

16. van Ballegooijen M, Habbema JD, van Oortmarssen GJ, Koopmanschap MA, Lubbe JT, van Agt HM. Preventive Pap-smears: balancing costs, risks and benefits. Br J Cancer. 1992;65:930-3.

17. Oscarsson M, Benzein E. Women's experiences of pelvic examination: an interview study. J Psychosom Obstet Gynaecol. 2002;23:17-25.

18. Kivistik A, Lang K, Baili P, Anttila A, Veerus P. Women's knowledge about cervical cancer risk factors, screening, and reasons for non-participation in cervical cancer screening programme in Estonia. BMC Womens Health. 2011;11:43.

19. Dobrossy L, Kovacs A, Budai A, Cornides A. [Gynecological screening or cervical screening? Conflicts between clinical and public health viewpoints]. Orv Hetil. 2012;153:1302-13. Hungarian.

20. Valerianova Z, Panayotova Y, Amati C, Baili P. Cervical cancer screening in Bulgaria-past and present experience. Tumori. 2010;96:538-44.

21. Bruni L, Albero G, Aldea M, Serrano B, Valencia S, Brotons M, et al. ICO Information Centre on HPV and Cancer (HPV Information Centre). Human papillomavirus and related diseases in Latvia. Summary report 2015-03-20. 2015 [cited $2015 \mathrm{Apr}$ 11]. Available from: https://www.hpvcentre.net/statistics/reports/LVA.pdf.

22. Craciun C, Baban A. "Who will take the blame?": understanding the reasons why Romanian mothers decline HPV vaccination for their daughters. Vaccine. 2012;30:6789-93.

23. Arbyn M, Xu L, Simoens C, Martin-Hirsch PPL. Prophylactic vaccination against human papillomaviruses to prevent cervical cancer and its precursors. Cochrane Database of Syst Rev. 2018;5:CDoo9069.

24. Spencer AM, Brabin L, Verma A, Roberts SA. Mothers' screening histories influence daughters' vaccination uptake: an analysis of linked cervical screening and human papillomavirus vaccination records in the north west of England. Eur J Cancer. 2013;49:1264-72.

25. Marvan ML, Ehrenzweig Y, Catillo-Lopez RL. Knowledge about cervical cancer prevention and psychosocial barriers to screening among Mexican women. J Psychosom Obstet Gynaecol. 2013;34:163-9.

26. O'Connor M, Murphy J, Martin C, O'Leary J, Sharp L. Motivators for women to attend cervical screening: the influential role of GPs. Fam Pract. 2014;31:475-82. 